\title{
Knowledge, attitude and practice of breast cancer screening among female general practitioners in Riyadh, Saudi Arabia
}

\author{
Mohammed Yehia Saeedi ${ }^{1}$, Fahad Al Amri ${ }^{1}$, Ahmed Khair Ibrahim ${ }^{2,}$, , Kassim Kassim ${ }^{1}$ \\ ${ }^{1}$ Deputy Ministry for Public Health, Assistant Deputy for Primary Health Care, Ministry of Health, Riyadh, Saudi Arabia \\ ${ }^{2}$ Public Health \& Community Medicine School, Faculty of Medicine, Assiut University, Asyut, Egypt
}

\section{Email address:}

ahmed.ibrahim7@med.au.edu.eg (A. K. Ibrahim), ahmed.khair@yahoo.com (A. K. Ibrahim)

\section{To cite this article:}

Mohammed Yehia Saeedi, Fahad Al Amri, Ahmed Khair Ibrahim, Kassim Kassim. Knowledge, Attitude and Practice of Breast Cancer Screening among Female General Practitioners in Riyadh, Saudi Arabia. Cancer Research Journal. Vol. 2, No. 6, 2014 , pp. $108-113$. doi: 10.11648/j.crj.20140206.13

\begin{abstract}
Background: Breast cancer has been ranked as the $1^{\text {st }}$ cancer in women in Kingdom of Saudi Arabia. Screening, early detection and proper treatment of Breast Cancer was associated with more chances of better prognosis and long-term survival. The role general practitioner's role is to provide professional knowledge, skills and support for patients as well as their caregiver about screening and prevention. This study aimed to investigate the level of knowledge of Breast Cancer risk factors, beliefs, diagnosis and practice of Breast Self Examination, Clinical Breast Examination and mammography among female General Practitioners who are currently working in primary health care center in Riyadh city, Kingdom of Saudi Arabia. Methods: A cross-sectional study was conducted using a self-administered questionnaire among female physicians, currently working as General Practitioners in Primary Health Care centers were invited. Descriptive statistics: mean, standard deviation, frequencies, percentage were calculated. Results: The majority (90\%) of the respondents believed that Breast Cancer is a major health problem and $96 \%$ were aware of the importance of mammography as a screening method. But only $19 \%$ of the studied physicians requested mammogram as screening tool for women aged 40 years or more. Conclusion: The current study demonstrated that knowledge about breast cancer screening was satisfactory and highlighted the need for the provision of continuing medical education programs to improve the general practitioners' practice on cancer screening tools.
\end{abstract}

Keywords: Breast Cancer, Mammography, Screening and General Practitioner

\section{Introduction}

Breast cancer $(\mathrm{BC})$ is considered to be one of the most common malignancies and the second leading cause of cancer deaths in women after lung cancer, worldwide. It forms about $23 \%$ of all female cancers [1-3]. Breast cancer has become a significant problem in both developed and developing countries and the incidence rates are high in most of the developed areas [4]. The American Cancer Society (ACS) reported that one in eight women (12.3\%) in the USA will develop breast cancer once in her lifetime and about 232,340 new cases of invasive BC discovered annually. Moreover, around 39 thousand $\mathrm{BC}$ deaths were expected among American women in 2013 [5].

The Kingdom of Saudi Arabia (KSA) is no exception, where $\mathrm{BC}$ has been ranked as the most common cancer in females according to the Saudi Cancer Registry (SCR) in 2012 [6]. It has been reported that BC accounted for $25 \%$ of all newly diagnosed female cancers $(5,205)$ in 2009 . The median age at diagnosis was 48 years (19-99 years) with agestandardized rate (ASR) 22.7/100,000 [6,7]. The highest ASR was recorded in five regions, Eastern region at 33.1/100, 000, Riyadh region at 29.4/100, 000, Makah region at 26.4/100,000, Qassim region at 25/100,000 and Jouf region at $22.5 / 100,000[6,7]$.

Gulf Cooperation Council (GCC) countries reported that about 4480 BC cases were diagnosed during the period 19982002. BC represented $16.1 \%$ of all female cancers in Oman and $35.4 \%$ in Bahrain. The ASR per 100,000 was highest in Bahrain (46.4), followed by Kuwait (44.3), Qatar (35.5), 
United Arab Emirates (19.2), Oman (14.4) and Saudi Arabia (12.9). These rates were lower compared with those of the most industrialized Western countries [7, 8]. The incidence increased after the introduction of mammography screening and continues to do so with the aging of the population [9]. Despite the low rate in the KSA, it was estimated that, by $2025, \mathrm{BC}$ rate will be increased by around $350 \%$ and $\mathrm{BC}$ specific mortality by around $160 \%[10,11]$.

ACS guidelines for early detection of $\mathrm{BC}$ in average-risk women consisted of a combination of regular clinical breast examination (CBE), counseling to raise awareness about $\mathrm{BC}$ symptoms beginning in the early twentieth and annual mammography beginning at the age of $40[12,13]$. Women should undergo CBE every 3 years between the ages of 20 and 39 and annually after the age of 40 [14]. It should be part of the periodic health examinations [13, 14]. Breast selfexamination (BSE) as a screening method is controversial. Data from a large randomized trial on BSE screening in Shanghai, china revealed that instruction in BSE has no effect on reducing breast cancer mortality [15].

Early detection and proper treatment of BC was associated with more chances for better prognosis and long-term survival [16]. The aim of BC screening is to advance the time of diagnosis so for earlier intervention leading to better prognosis [17]. However, earlier diagnosis leads to an increase in the apparent incidence of BC and resulted in leadtime bias, even if screening does not confer any benefit [18].

The role of the general practitioner (GP) is to provide professional knowledge, skills and support for patients as well as their caregiver about screening and prevention. Advocating for the patient and coordination of care is considered to be vital roles for GPs [19]. Consonant evidence showed that higher cancer screening participation rates were associated with greater involvement of primary care. Primary care providers are pivotal in reducing diagnostic delay, particularly in health systems that have long waiting times for outpatient diagnostic services. Several randomized controlled trials have shown primary care-led follow-up care to be equivalent to hospital-led care in terms of patient wellbeing, recurrence rates and survival, and might be less costly [20].

\subsection{Aim}

The current work aimed to investigate the level of knowledge of $\mathrm{BC}$ risk factors, beliefs concerning $\mathrm{BC}$ diagnosis and practice of $\mathrm{BSE}, \mathrm{CBE}$ and mammography among female GPs, working in primary health care centers in Riyadh city, KSA.

\section{Materials and Methods}

\subsection{Study Design and Study Population}

A cross-sectional stud protocol was approved by Institutional Review Board (IRB) of the King Saud University (KSU) No. 14/4048/IRB. All female primary health (PHC) physician $(\mathrm{N}=180)$, who are currently working as GPs in PHC centers.

\subsection{Data Collection}

A pre-coded designed questionnaire was used to collect information from all participants. An invitation letter was attached to the questionnaire to explain the research objective, methods and expected benefits. The questionnaire was distributed then collected via the Cancer program coordinators in Riyadh city. All female GPs working in PHC centers of Riyadh city $(n=180)$ were invited and they were completely free to opt to participate or withdraw, without any consequence at any time prior to or at any point during or after the activity. They were informed that any information provided will be kept confidential and will be used only for the research purposes and will not be used in any way that can identify them.

\subsection{Survey Instrument}

The study questionnaire was adapted, after modification, from questionnaires used in similar studies carried out in the $\mathrm{KSA}$ and other countries. Literature review was used to add items on information of $\mathrm{BC}$ prevention and screening for questionnaire modification. Our study questionnaire is composed of 30 questions distributed over four sections as follows;

1 Socio-demographic data: age, marital status, job title, nationality and category of PHC

2 Knowledge of $B C$ screening: different risk for $\mathrm{BC}$ were included; family history of $\mathrm{BC}$, number of $1^{\text {st }}$ degree relative with $\mathrm{BC}$ [14], Chest exposure to radiation, previous history of $\mathrm{BC}$, breast feeding, age at first live birth, use of hormonal replacement therapy, obesity, benign breast disease [21], parity, early age at menarche, late age of menopause, begin a female and age at married [22]

3 Attitude of GPs regarding BC screening and diagnosis

4 The last section addressed the topic of GPs practice and was designed to elicit similar response of always, infrequent and never

\subsection{Statistical Analysis}

Data was verified and coded by the researcher. Analysis was carried out using the Statistical Package for Social Sciences (SPSS/PC/VER 21) [23]. To minimize data entry errors, check codes were incorporated into the database and the data were cleaned to ensure consistency of responses. Again, Frequency tables were examined to explore missing data, errors in the data and data consistency.

For questions that were unanswered, responses were left blank during data entry and treated as missing in the final analysis. Similarly, if more than one answer was selected, this was left blank during data entry and treated also as missing. Ten participants who failed to complete the majority of items were not included in the final analysis.

It has been proposed that for purposes of analysis replacing missing values can reduce bias and often is used 
for this purpose if data are missing at random [24]. Descriptive statistics: mean, standard deviation, frequencies, percentage were calculated to the differences in KAP among the study participants.

\section{Results}

The study was carried out in Riyadh city for four months. All female PHC physicians were invited to participate $(n=180)$. The response rate was $73.8 \%(n=133)$ and the completeness rate after excluding incomplete questionnaires was $91.7 \%(n=123)$.

Socio-demographic characteristics of the study participants were summarized in Table 1. Age ranged between 24 and 63 years (Mean $=40.2 \pm 7.8)$, and a total (92.7\%) were currently married. All participants possessed basic professional certificate while( $48 \%$ ) had additional postgraduate qualification in internal medicine, pediatric and Gynecology. Average length of practicing after graduation was $(17.6 \pm 6.7)$.

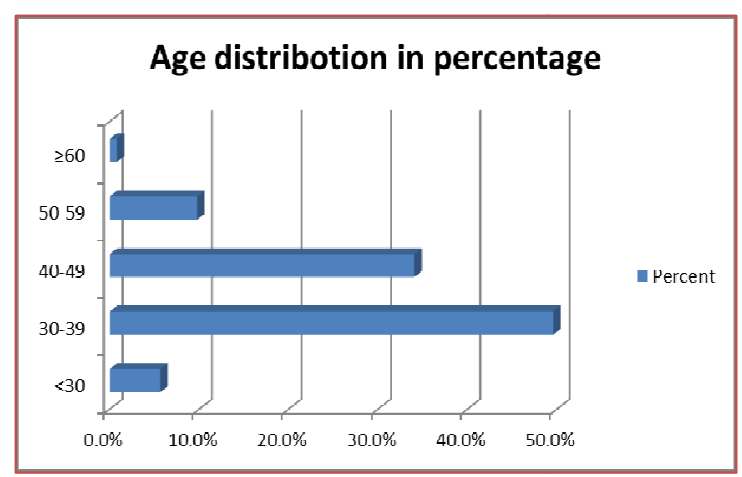

Figure (1). Percentage of participant's age groups in the current study

Table 2 depicted the participants' knowledge of breast cancer risk factors, signs and symptoms of $\mathrm{BC}$ and screening methods. The majority of respondents $(90 \%)$ believed that $\mathrm{BC}$ is a major health problem and the most common cancer among female in the KSA. For the knowledge of $\mathrm{BC}$ risk factors, $82.1 \%$ of the participants identified increasing age as a risk factors while $113(91.9 \%)$ recognized family history of breast cancer as $\mathrm{BC}$ risk factor. Other risk factors were recognized by less than $60 \%$ of participants. The least recognized risk factor was being non-married (48.8\%). More than $(86 \%)$ participants were aware of the signs and symptoms that may be suggestive for BC. About $96 \%$ were aware of the importance of mammography as a screening method for breast cancer and $84.6 \%$ knew that the recommended age to start annual screening by mammography is 40 . Ninety percent believed that BSE is an effective tool for $\mathrm{BC}$ diagnosis. Around $71 \%$ believed that regular $\mathrm{CBE}$ should be started at the age of 40 and annually.

Table (1). Socio-demographic characteristics of participants

\begin{tabular}{|c|c|c|c|}
\hline Variable & & Frequency & $\%$ \\
\hline \multirow{5}{*}{ Age in years } & $<30$ & 7 & $5.7 \%$ \\
\hline & $33-39$ & 61 & $49.6 \%$ \\
\hline & $40-49$ & 42 & $34.1 \%$ \\
\hline & $50-59$ & 12 & $9.8 \%$ \\
\hline & $\geq 60$ & 1 & $0.8 \%$ \\
\hline \multirow{5}{*}{ Marital status } & Single & 3 & $2.4 \%$ \\
\hline & married & 114 & $92.7 \%$ \\
\hline & Divorced & 4 & $3.3 \%$ \\
\hline & Window & 1 & $0.8 \%$ \\
\hline & missing & 1 & $0.8 \%$ \\
\hline \multirow{3}{*}{ Nationality } & Saudi & 9 & $7.3 \%$ \\
\hline & Non Saudi & 112 & $91.1 \%$ \\
\hline & Missing & 2 & $1.6 \%$ \\
\hline \multirow{4}{*}{$\begin{array}{l}\text { Practice after } \\
\text { graduation }\end{array}$} & $\leq 10$ years & 46 & $37.4 \%$ \\
\hline & $11-20$ & 60 & $48.8 \%$ \\
\hline & $21-30$ & 15 & $12.2 \%$ \\
\hline & $>30$ & 2 & $1.6 \%$ \\
\hline \multirow{3}{*}{$\begin{array}{l}\text { Professional } \\
\text { qualification }\end{array}$} & Basic & 58 & $47 \%$ \\
\hline & Postgraduate & 59 & $48 \%$ \\
\hline & Missing & 6 & $4.9 \%$ \\
\hline \multirow{4}{*}{$\begin{array}{l}\text { Category of the } \\
\text { PHC center }\end{array}$} & A & 28 & $35.0 \%$ \\
\hline & B & 35 & $43.8 \%$ \\
\hline & $\mathrm{C}$ & 14 & $17.5 \%$ \\
\hline & $\mathrm{D}$ & 3 & $3.8 \%$ \\
\hline \multirow{3}{*}{ Specialty } & Internal medicine & 11 & $8.9 \%$ \\
\hline & Family medicine & 64 & $52 \%$ \\
\hline & Others & 48 & $39 \%$ \\
\hline
\end{tabular}

Table (2). Knowledge of BC risk factors

\begin{tabular}{|c|c|c|}
\hline Variable & Frequency & $\%$ \\
\hline $\mathrm{BC}$ is the most common cancer among female in $\mathrm{KSA}$ & 111 & 90.2 \\
\hline \multicolumn{3}{|l|}{ Risk factor } \\
\hline Old age & 101 & $82.1 \%$ \\
\hline Early age of menarche & 76 & $61.7 \%$ \\
\hline late age at menopause & 93 & $75.6 \%$ \\
\hline Increase breast density & 107 & $78 \%$ \\
\hline Begin a female & 75 & $61 \%$ \\
\hline Being non married & 60 & $48.8 \%$ \\
\hline Nulliparity & 90 & $73.1 \%$ \\
\hline Hormonal replacement therapy & 71 & $57.7 \%$ \\
\hline Family history of breast cancer & 113 & $91.9 \%$ \\
\hline Radiation exposure to chest & 79 & $64.2 \%$ \\
\hline \multicolumn{3}{|l|}{ Signs and symptoms that may be suggestive BC } \\
\hline Breast lump & 106 & $86.2 \%$ \\
\hline Recent nipple retraction & 111 & $90.2 \%$ \\
\hline Bloody discharge from nipple & 116 & $94.3 \%$ \\
\hline Skin discoloration & 107 & $87 \%$ \\
\hline
\end{tabular}




\begin{tabular}{lll}
\hline Variable & Frequency & $\mathbf{\%}$ \\
\hline BC is the most common cancer among female in KSA & $\mathbf{1 1 1}$ & $\mathbf{9 0 . 2}$ \\
\hline Mammography is the best way for screening method for breast cancer & 118 & $95.9 . \%$ \\
The recommended age for mammography to started at the age of 40 and annually & 104 & $84.6 \%$ \\
The breast clinical examination is recommended annually after age of 40 & 88 & $71.5 \%$ \\
Breast self-examination is an effective tool for diagnosis of breast cancer & 111 & $90.2 \%$ \\
\hline
\end{tabular}

Participants' responses to inquires about attitude regarding BC screening were illustrated in tables 3. Ninety one participants $(91 \%)$ have advised at least one member of their families to undergo $\mathrm{BC}$ screening. About $85 \%$ believed that $\mathrm{BC}$ can be diagnosed by PHC physician. About two thirds of the study cohort thought that their patients are aware of BC screening. Less than half (45.5\%) were subscribed in at least one international medical journal and only $59 \%$ were aware about Saudi guideline for BC management.

Table (3). Attitude regarding BC screening

\begin{tabular}{lll}
\hline Variable & Frequency & $\%$ \\
\hline $\begin{array}{l}\text { Breast cancer can be diagnosed by primary } \\
\text { health care physician? }\end{array}$ & 104 & $84.6 \%$ \\
$\begin{array}{l}\text { Do you think that your patients are aware of } \\
\text { breast cancer? }\end{array}$ & 79 & $64.2 \%$ \\
$\begin{array}{l}\text { Did you aware of Saudi guideline for breast } \\
\text { cancer management? }\end{array}$ & 73 & $59.3 \%$ \\
$\begin{array}{l}\text { Do you have any subscription in any medical } \\
\text { journal or medical website? }\end{array}$ & 56 & $45.5 \%$ \\
$\begin{array}{l}\text { Have you ever advised a family member to } \\
\text { undergo a mammogram }\end{array}$ & 91 & $74 \%$ \\
Early diagnosis of BC affects survival. & 118 & $95.9 \%$ \\
\hline
\end{tabular}

Tables 4 summarized the results of the questionnaire bout GPs practices. It showed that more than $70 \%$ of doctors were looking for the clinical signs of $\mathrm{BC}$ during $\mathrm{CBE}$ and less than $30 \%$ do not. Moreover, $69 \%$ asked about the most common risk factors as part of their routine medical history taking. Around $83.7 \%$ advised women to perform SBE. Only $19 \%$ of the studied physicians requested routine mammogram screening for all patients aged 40 years or more.

Table (4). Practice of physicians regarding history taking, CBE and mammography

\begin{tabular}{lcc}
\hline \multicolumn{2}{c}{ Yes } & No \\
\hline Did you ask about the following during medical history taking? \\
Age at menopause & $45 \%$ & $55 \%$ \\
Breast feed & $80.2 \%$ & $19.8 \%$ \\
Being pregnant & $71.9 \%$ & $28.1 \%$ \\
Family history of BC & $78.5 \%$ & $21.5 \%$ \\
Did you often look for the following signs of breast cancer during clinical \\
examination & & \\
Breast lump & $76.4 \%$ & $23.6 \%$ \\
Nipple discharge & $76.9 \%$ & $23.1 \%$ \\
Axillary lymph node & $73.6 \%$ & $26.4 \%$ \\
Nillpe inversion & $75.2 \%$ & $24.8 \%$ \\
Skin dimpling & $73.6 \%$ & $26.4 \%$ \\
Did you request mammogram screening for all patients 40 years and above \\
\end{tabular}

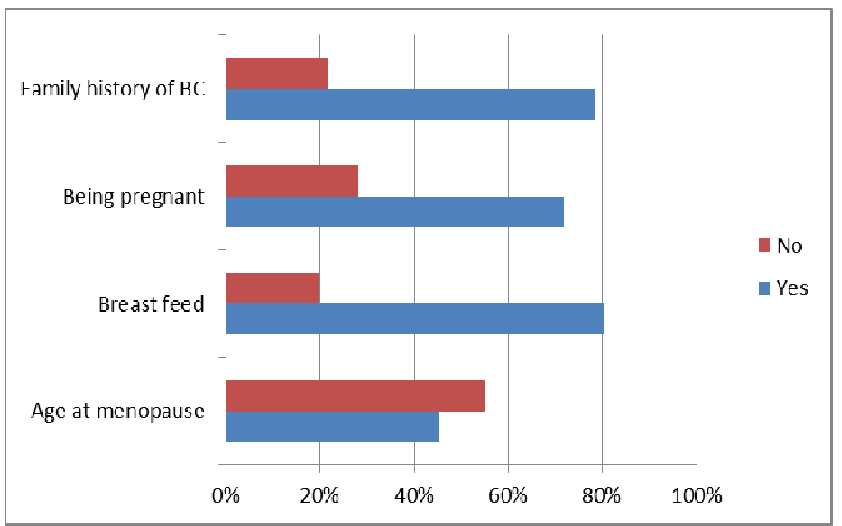

Figure 2. Identified risk factors during medical history taking

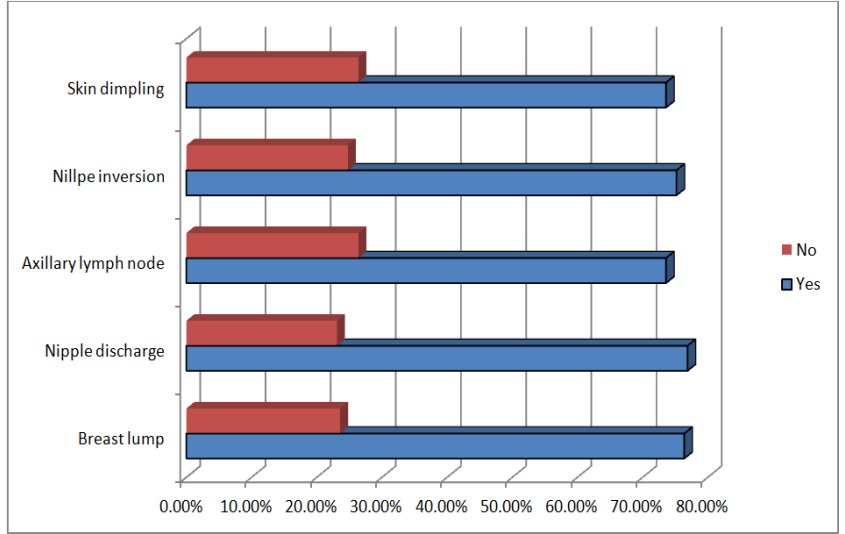

Figure 3. Percentage of looking for signs of BC during clinical examination

\section{Discussion}

The main goal of $\mathrm{BC}$ screening program is to detect cancers cases at early stage or even before starting of symptoms. The patient's survival and line of treatment depend heavily on early diagnosis. BCE, BSE and mammography were recognized as effective screening methods for $\mathrm{BC}$ and the adoption of mammography screening has led to reduction in mortality from the disease in women over 50 years [25]. Knowledge level, attitude and practice of health care providers toward BCS are important factors in the control of breast cancer. It was proposed that health will be improve in a society in which health personnel play an active role in health education and peruse a good role model in the society [26]. GPs should be aware of the BC risk factors in order to guide the patients for the necessary screenings modalities [3].

The current work was carried out to know the level of knowledge, beliefs and practice among all female GPs $(n=123)$ who are working in PHC in Riyadh city toward BCS 
from Feb. to June 2014. The majority of participants (90.2\%) believed that $\mathrm{BC}$ is the most common cancer among female in KSA, this was consistent with study in Morocco published in 2011, in which all doctors $(n=44)$ believed that $B C$ is a major health problem in their country [27]. Another study in Nigeria in 2009 reported that $86.7 \%$ had the same believe [28].

The most common risk factors for $\mathrm{BC}$ identified by participants were; family history of BC $(91.9 \%)$, old age $(82.1 \%)$, increase breast density $(78 \%)$, late age at menopause (75.6\%) and radiation exposure $(64.2 \%)$. The least known were: hormonal replacement therapy (57.7\%) and nulliparity (48.8\%). A similar study in Morocco showed that the all participants $(100 \%)$ identified the fallowing as risk factors for $\mathrm{BC}$, family history of $\mathrm{BC}$, late age at menopause, nulliparity, early menarche at the age of less 12 years, history of previous benign breast lump and use of oral contraceptive pills. The least known were old age and first childbirth at the age of 30 years (44\%)[27]. In contrast, the Nigerian study showed that $(95.6 \%)$ of doctors identified increasing age as a risk factor while (80\%) recognized current use of oral contraceptive pills as breast cancer risk factor. Other risk factors were recognized by less than threequarters of participants. The least recognized risk factors were nulliparity $(73.3 \%)$ and advanced age at first childbirth (57.8\%) [28]. An Australian study revealed that GPs have limited knowledge about some aspects of BC risk factors with only quarter of them recognized increasing age as breast cancer risk factor [29]. In the United Kingdom, a study of General Practitioner's knowledge about BC risk factors showed that more than half of the participants were able to correctly identify risk factors assessed [30].

The American cancer society guidelines for cancer screening recommended annual mammogram and $\mathrm{CBE}$ for women above the age of 40 years. Furthermore, monthly BSE is made optional with emphasis on the importance of breast self-awareness outside a structured BSE [30]. In the current study the majority of participants (96\%) were aware of the importance of mammography as a screening tool for $\mathrm{BC}$ and $84.6 \%$ knew that the recommended age to start screening is 40 years and annually but only $19.1 \%$ requested mammogram as screening for all patients 40 years and above due to unavailability of mammogram in PHC center or lack of cooperation and social and cultural barrier. Similar results reported in 2011 by Meissner, et al., in the USA where $94.6 \%$ of general Practitioner recommended mammography to women aged 40 to 49 years on an annual basis and $99.5 \%$ recommended annual mammography to women aged $>50$ years [31].

Ninety percent of participants knew that BSE is an effective tool for diagnosis of $\mathrm{BC}$ while $71.5 \%$ believed that regular $\mathrm{CBE}$ should be started at age of 40 and should be carried annually. Cockburn et al., reported that $95 \%$ of general practitioners believed that $\mathrm{BSE}$ and $\mathrm{BCE}$ were important for asymptomatic women of more than 45 years of age compared with the $75 \%$ of respondents who viewed mammography in the same way as a screening method for early breast cancer[29]. In Meissner's study, the majority of primary care physicians $(96.5 \%)$ recommended annual CBE to all women aged $>40$ years [31]. Ghanem, et al., in 2011 found that all participated physician were aware of BSE and CBE [32]. In current study $95.9 \%$ of participants believed that early detection and treatment of breast cancer affects survival. Also, all participants (100\%) in Ghanem, et al., study believed that $\mathrm{BC}$ is curable if detected early [27] and $91.1 \%$ in Ibrahim et al., [28].

Primary care physicians played a key role in performing and referring patients for cancer screening and previous research indicated that the practices of physicians and other healthcare providers were not necessarily consistent with clinical guidelines [32]. Furthermore, it is unknown to what extent clinical guidelines motivate physician's practice or which barriers or facilitators to implementation of clinical guidelines were associated with changes in practice recommendations [31, 33]. In the current study, $45.5 \%$ subscribed in at least one of the international medical journal and only $59.3 \%$ of participants were aware about Saudi guideline for breast cancer management. But, in a study by Meissner et al., most of the PHC (82.5\%) identified at least one $\mathrm{BC}$ screening guideline as being very influential in their practice [31]. About $75 \%$ of participants of the current study have advised at least one member of their families to undergo a mammogram and $83.7 \%$ have advised their patients regularly to perform SBE which is higher than that of AlAmoudi's study where only $63.5 \%$ did [10].

The National Comprehensive Cancer Network (NCCNI) group continues to recommend $\mathrm{CBE}$ for BC screening [14]. More importantly, preliminary results from a new cluster randomized trial from Mumbai, India suggested that $\mathrm{CBE}$, in fact, facilitates the down-staging of breast cancer in countries where women were commonly presented with advanced stage disease at time of diagnosis [10]. In the current study more than $70 \%$ of doctors looked for the clinical signs of BC during CBE but in Al-Amoudi 's study 78.4\% perform breast examination if there is a complaint and $11.3 \%$ for every patient [10].

\section{Conclusion}

Up to our knowledge this is the first study to investigate the knowledge, attitude and practice of female GPs in PHC centers regarding BC in Riyadh, KSA. We anticipated that it will provide a baseline to monitor changes over time. The results demonstrated that the knowledge of breast cancer risk factors was satisfactory. A bigger study is recommended to cover all GPs in the KSA to monitoring their beliefs, attitude, and practices and understand how best to incorporate the latest scientific evidence regarding breast cancer prevention and early detection into healthcare practice. Also, a future survey should be conducted to compare the level of knowledge among GPs with different socio-demographic and professional characters. 


\section{References}

[1] Bray, F., et al., Global estimates of cancer prevalence for 27 sites in the adult population in 2008. Int J Cancer, 2013. 132(5): p. 1133-45.

[2] Soerjomataram, I., et al., Global burden of cancer in 2008: a systematic analysis of disability-adjusted life-years in 12 world regions. Lancet, 2012. 380(9856): p. 1840-50.

[3] Stojadinovic, A., et al., Consensus recommendations for advancing breast cancer: risk identification and screening in ethnically diverse younger women. J Cancer, 2011. 2: p. 210-27.

[4] Cancer Facts \&Figures. Atlanta: American Cancer Society, in2012.

[5] DeSantis, C., et al., Breast cancer statistics, 2013. CA Cancer J Clin, 2014. 64(1): p. 52-62.

[6] Al-Eid , H., Cancer Incidence Report Saudi Arabia 2009 S. Bazarbashi and A. Al-Zahrani, Editors. decemcer 2012.

[7] Ravichandran, K. and A.S. Al-Zahrani, Association of reproductive factors with the incidence of breast cancer in Gulf Cooperation Council countries. East Mediterr Health J, 2009. 15(3): p. 612-21.

[8] Abdurrahman Al Diab, S.Q., Khalid A. Al Saleh,, A.A. Farjah H. Al Qahtani, Mohammed A. Alghamdi, A. Alsaif,, and V.F.Q.a.M.R.Q. Areej A. Bokhari, Review on Breast Cancer in the Kingdom of Saudi Arabia. Middle-East Journal of Scientific Research, 2013. 14 ((4)): p. 532-543.

[9] E. Senkus1, S.K., F. Penault-Llorca3,4, P. Poortmans5, A. Thompson6, S. Zackrisson7 \& F. Cardoso8,9, on behalf of the ESMO Guidelines Working Group*, Primary breast cancer: ESMO Clinical Practice Guidelines for diagnosis, treatment and follow-upt. Annals of Oncology, August 2013. 24 ((Supplement 6)): p. vi7-vi23.

[10] Al-Amoudi, S.M., W.A. Sait, and H.S. Abduljabbar, Health care provider's role in facing the future burden of breast cancer in Saudi. Saudi Med J, 2010. 31(12): p. 1359-62.

[11] Ibrahim, E.M., et al., The present and the future of breast cancer burden in the Kingdom of Saudi Arabia. Med Oncol, 2008. 25(4): p. 387-93.

[12] Chiarelli, A.M., et al., The contribution of clinical breast examination to the accuracy of breast screening. J Natl Cancer Inst, 2009. 101(18): p. 1236-43.

[13] Smith, R.A., et al., Cancer screening in the United States, 2010: a review of current American Cancer Society guidelines and issues in cancer screening. CA Cancer J Clin, 2010. 60(2): p. 99-119.

[14] Bevers, T.B., et al., NCCN clinical practice guidelines in oncology: breast cancer screening and diagnosis. J Natl Compr Canc Netw, 2009. 7(10): p. 1060-96.

[15] Thomas, D.B., et al., Randomized trial of breast selfexamination in Shanghai: final results. J Natl Cancer Inst, 2002. 94(19): p. 1445-57.

[16] Mittra, I., et al., A cluster randomized, controlled trial of breast and cervix cancer screening in Mumbai, India: methodology and interim results after three rounds of screening. Int J Cancer, 2010. 126(4): p. 976-84.

[17] Independent, U.K.P.o.B.C.S., The benefits and harms of breast cancer screening: an independent review. Lancet, 2012. 380(9855): p. 1778-86.

[18] Marmot, M.G., et al., The benefits and harms of breast cancer screening: an independent review. Br J Cancer, 2013. 108(11): p. $2205-40$.

[19] Group., N.Z.G., Suspected Cancer in Primary Care: Guidelines for investigation, referral and reducing ethnic disparities. Ministry of Health, Wellington, 2009.

[20] Emery, J.D., et al., The role of primary care in early detection and follow-up of cancer. Nat Rev Clin Oncol, 2014. 11(1): p. $38-48$.

[21] Singletary, S.E., Rating the risk factors for breast cancer. Ann Surg, 2003. 237(4): p. 474-82.

[22] Richie, R.C. and J.O. Swanson, Breast cancer: a review of the literature. J Insur Med, 2003. 35(2): p. 85-101.

[23] IBM-SPSS. Statistical package for social science. Ver.21. Standard version. SPSS Inc.; 2012, .

[24] P, A., Missing data, Sage University Series on Quantative Applications in the Social Sciences. . 2001: Sage Publications, Thousand Oaks, CA.

[25] Olsen, A.H., et al., Breast cancer mortality in Copenhagen after introduction of mammography screening: cohort study. BMJ, 2005. 330(7485): p. 220.

[26] Koçak S, Ç.L., Özbaş S, et al, Risk factors in breast cancer, risk assessment and prevention: 2010 Istanbul consensus meeeting report. The J of Breast Health, 2011. 7: p. 47-67.

[27] Ghanem, S., et al., Knowledge of risk factors, beliefs and practices of female healthcare professionals towards breast cancer, Morocco. Pan Afr Med J, 2011. 10: p. 21.

[28] Ibrahim, N.A. and O.O. Odusanya, Knowledge of risk factors, beliefs and practices of female healthcare professionals towards breast cancer in a tertiary institution in Lagos, Nigeria. BMC Cancer, 2009. 9: p. 76.

[29] Cockburn, J., et al., Encouraging attendance at screening mammography: knowledge, attitudes and intentions of general practitioners. Med J Aust, 1989. 151(7): p. 391-6.

[30] Bekker, H., L. Morrison, and T.M. Marteau, Breast screening: GPs' beliefs, attitudes and practices. Fam Pract, 1999. 16(1): p. 60-5.

[31] Meissner, H.I., et al., Breast cancer screening beliefs, recommendations and practices: primary care physicians in the United States. Cancer, 2011. 117(14): p. 3101-11.

[32] Richards, M.A., et al., Influence of delay on survival in patients with breast cancer: a systematic review. Lancet, 1999. 353(9159): p. 1119-26.

[33] Klabunde, C.N., M.S. O'Malley, and A.D. Kaluzny, Physicians' reactions to change in recommendations for mammography screening. Am J Prev Med, 1997. 13(6): p. 432-8. 